\title{
Overall survival (OS) in patients after chemotherapy for cervical cancer in Poland in years 2008-2015
}

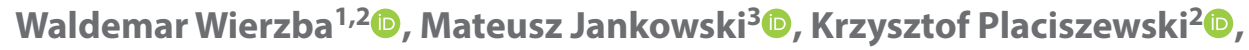

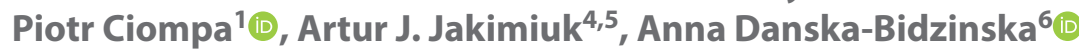 \\ ${ }^{1}$ University of Humanities and Economics in Lodz, Poland \\ ${ }^{2}$ Central Clinical Hospital of the Ministry of Internal Affairs and Administration, Warsaw, Poland \\ ${ }^{3}$ School of Public Health, Centre of Postgraduate Medical Education, Warsaw, Poland \\ ${ }^{4}$ Department of Obstetrics and Gynecology, Central Clinical Hospital of Interior Affairs and Administration, Warsaw, Poland \\ ${ }^{5}$ Center of Reproductive Health, Institute of Mother and Child, Warsaw, Poland \\ ${ }^{6}$ Chair and Department of Obstetrics, Gynaecology and Oncology, $2^{\text {nd }}$ Faculty of Medicine, \\ Medical University of Warsaw, Poland
}

\begin{abstract}
Objectives: To analyze cervical cancer prevalence as well as treatment methods, and its effects and assessment of overall survival of patients after chemotherapy for cervical cancer in Poland.

Material and methods: Data were collected from the registry of the National Health Fund (the only public payer in Poland). The data of patients treated in 2008-2015, who were shown to the payer with the diagnosis of malignant neoplasm of cervix (C53 according to the ICD-10 classification), were included in the analysis. The annual and eight-year prevalence rates were calculated. The overall survival was calculated for patients treated with chemotherapy.

Results: In the analyzed period (2008-2015), 83,100 women were diagnosed with C53, of which 33,300 (40\%) were reported in the group of hospital treatment. The median age of patients was 59 years $(58.8 \pm 12.87)$. The highest prevalence rate was observed in 2008 (16.94 patients/100,000 inhabitants). The highest annual and period (2008-2015) prevalence rates patients per 100,000 inhabitants were observed in the Podlaskie (17.03 and 115.53 respectively) and Pomorskie (14.19 and 101.43 respectively) voivodeships and the lowest in Dolnośląskie voivodeship (10.47 and 78.87 respectively) and Podkarpackie voivodeship (10.79 and 71.29 respectively). Mean survival time was 55.12 months and its median 45.46 months. Annual survival time was observed in $76.79 \%$ of patients, 2-year in $60.61 \%$; 3 -year in $53.08 \%$ and 5 -year in $46.65 \%$.

Conclusions: In the years 2008-2015 in Poland, the incidence of cervical cancer was even 4 times higher than the EU average, and the mortality was as much as $70 \%$ higher than the average for EU countries.

Key words: cervical cancer; epidemiology; survival rate; Poland
\end{abstract}

Ginekologia Polska 2022; 93, 7: 540-545

\section{INTRODUCTION}

Cervical cancer (cancer of cervix uteri) belongs to the group of the most common neoplasms in the world population, it is the fourth most commonly occurring cancer in women and the eighth most commonly occurring cancer overall [1-4]. According to the World Health Organization (WHO) data, in 2008 there were 530,000 new cases in the world and 275,000 deaths recorded due to cervical cancer $[1,2]$. More than $85 \%$ of new cases affected women living in developing countries, but the highest incidence rates were recorded in African countries (35/100,000), South America $(23.9 / 100,000)$ and Central-South Asia $(24.6 / 100,000)$. The lowest incidence rates were observed in Western Asia, Australia and New Zealand $(6.0 / 100,000)[1,4]$.

The global burden of cervical cancer is increasing in 2018,570,000 new cases and 311,000 deaths were reported worldwide [3]. In 2020 the number of new cases of cervical cancer exceeded 600,000 [3]. It is estimated, that in 2020, cervical cancer was the most diagnosed cancer in 23 countries and was the leading cause of cancer death in 36 countries [3].

\footnotetext{
Corresponding author:

Mateusz Jankowski

School of Public Health, Centre of Postgraduate Medical Education, Warsaw, Poland

e-mail: mateusz.jankowski@cmkp.edu.pl
} 
Although cervical cancer is relatively rare in high-income countries, cervical cancer continues to be an important public health problem in Europe [4]. In 2009, over 54,000 new cases of cervical cancer were registered in Europe which at that time was the fifth most common cancer in women in Europe in terms of incidence [5]. In the countries belonging to the European Union (EU), the number of new diagnoses was 31,000 and 13,000 women died from this neoplasm. In 2020 the burden of cervical cancer in the EU remained at a similar level - in 2020, 30,447 new cases were reported in the EU countries [5]. However, there is a markable disparity between the European populations in morbidity and mortality due to the cervical cancer, primarily due to differences in the prevalence of human papilloma virus (HPV) infection, cancer control strategies as well as an access to cervical cancer screening programs $[3,4]$. In 2020, the highest incidence of cervical cancer (age standardized rate per 100,000) was observed in Romania (32.3), Estonia (27.4) and Lithuania (26.8) and the lowest in Malta (5.7) and Finland (6.7) [5]. The highest mortality rates were recorded in Romania (16.9), Bulgaria (12.4) and Latvia (11.7) and the lowest in Finland (2.1) and Malta (2.2) [5].

Poland is one of the countries with an average incidence rate of this type of cancer, however, it has one of the highest incidence and mortality rates in Europe. In 2020, Poland was eight in the $E U$ in terms of the incidence of cervical cancer and fifth in terms of deaths from this cancer in the EU [5]. In Poland, the peak incidence of cervical cancer falls on the sixth decade of life. Recent years indicate an increase in the number of cases in the population of younger women (from 35 to 44 years of age). In addition, Poland has also one of the lowest five-year survival rates in Europe noted, which is a measure of cure rate of this cancer. It was only $48.3 \%$ with the European average of $62.1 \%$. The discussed parameter depends primarily on the stage of the tumor at the time of diagnosis, histopathological type with the assessment of the degree of maturity, depth of cervical tissues involvement and presence of metastatic lymph nodes [6]. High incidence and mortality from cervical cancer in some regions of the world are mainly related to socioeconomic conditions, education, low health awareness and lack of primary and secondary prevention in women living in those areas. Nevertheless, over the past 20 years, there has been a gradual decrease in both incidence and mortality from cervical cancer including Poland. This tendency is probably related to the improvement of the quality of cancer prevention (access to cytology tests) as well as systematically growing expenditures on health care, health promotion and access to newer drugs.

\section{Objectives}

The aim of the study was to analyze (1) cervical cancer prevalence as well as (2) treatment methods, and its effects and assessment of overall survival (OS) of patients after chemotherapy for cervical cancer in Poland based on the data contained in the reports from the National Health Fund.

\section{MATERIAL AND METHODS}

Data were collected from the registry of the National Health Fund - dataset of the only public payer in Poland, where all data on healthcare services provided under public healthcare services are recorded. From the reporting reports of the National Health Fund, the data of patients treated in 2008-2015, who were shown to the payer with the diagnosis C53\% (the "\%"sign replaces any number) — malignant neoplasm of cervix according to ICD-10 classification, were collected for analysis. Based on the patient's ID and the data from the Statistics Poland, a retrospective analysis was performed to calculate the annual and eight-year prevalence rates. All subsegments of the health market operating in Poland (types of services - Tab. 1), which were then limited to hospital treatment, were analyzed. The prevalence rates were calculated based on the number of pairs "patient's ID + ICD-10 diagnosis = C53\%*". The annual index was calculated separately for each year (unique patient ID in a given year reported with the analyzed ICD-10) and the period index for the years 2008-2015 (unique patient ID in the entire analyzed period shown with the described diagnosis). Data were presented for the whole country as well as individual administrative regions (16 voivodeships). Patients treated with chemotherapy were selected based on the data from hospitals and for which the probability of overall survival (OS) was calculated. The beginning of the observation was the date of their first given chemotherapy, the cut-off date was set for $30^{\text {th }}$ June 2016 . Analyzes were performed using software SAS Enterprise E.G.5.1. This study was carried out in accordance with the principles of the Declaration of Helsinki. As we were working on secondary, anonymous data collected at the voivodship level, written informed consent to participate in the study was not required.

\section{RESULTS}

In the analyzed period (2008-2015), medical entities in the entire health care system in Poland showed 83,100 women diagnosed with malignant neoplasm of cervix (C53), of which 33,300 were reported in the group of hospital treatment (approximately $40 \%$ ). The average annual number of patients showed high stability at the level of about 24,100 patients ( $S D= \pm 704$ ). The median age of patients was 59 years (mean 58.8; SD $= \pm 12.87$ ).

Annual and period (8-year) prevalence rate per 100,000 inhabitants for a given voivodeship was calculated for each region and year separately, with detailed information included in Table 2. These parameters in the analyzed period are characterized by negative dynamics. The high- 
Table 1. Types of healthcare services included offered to patients with cervical cancer included in the analysis

\begin{tabular}{|l|c|}
$\begin{array}{l}\text { Number according to the } \\
\text { National Health Fund }\end{array}$ & Type of healthcare service \\
\hline 1 & Primary care \\
\hline 2 & Ambulatory specialized services \\
\hline 3 & Hospital treatment \\
\hline 4 & Psychiatric care and treatment of addictions \\
\hline 5 & Medical rehabilitation \\
\hline 6 & Long-term care \\
\hline 7 & Dental treatment \\
\hline 9 & Emergency assistance and sanitary transport \\
\hline 10 & Preventive health programs \\
\hline 11 & Separately contracted services \\
\hline 12 & Supplied of orthopedic equipment, auxiliaries and medical technical measures \\
\hline 14 & Nursing and care services \\
\hline 15 & Palliative and hospice care \\
\hline 16 & Emergency Medical services \\
\hline 17 & Emergency assistance and sanitary transport from 2009 \\
\hline
\end{tabular}

Table 2. Incidence rate per 100,000 inhabitants for a given voivodeship in 2008-2015 and eight-year period morbidity (2008-2015)

\begin{tabular}{|l|l|l|l|l|l|l|l|l|l|l|}
\hline Voivodeship & $\mathbf{2 0 0 8}$ & $\mathbf{2 0 0 9}$ & $\mathbf{2 0 1 0}$ & $\mathbf{2 0 1 1}$ & $\mathbf{2 0 1 2}$ & $\mathbf{2 0 1 3}$ & $\mathbf{2 0 1 4}$ & $\mathbf{2 0 1 5}$ & Avarage & $\begin{array}{c}\mathbf{8} \text { year } \\
\text { indicator }\end{array}$ \\
\hline Dolnośląskie & $\mathbf{1 4 . 1 3}$ & $\mathbf{1 0 . 0 4}$ & $\mathbf{1 1 . 0 7}$ & $\mathbf{9 . 4 6}$ & $\mathbf{7 . 8 4}$ & $\mathbf{9 . 8 7}$ & $\mathbf{8 . 6 0}$ & 12.76 & 10.47 & 78.87 \\
\hline Kujawsko-Pomorskie & $\mathbf{1 7 . 7 5}$ & $\mathbf{1 5 . 1 7}$ & $\mathbf{1 4 . 9 8}$ & 14.98 & 14.93 & 14.26 & 13.59 & 15.45 & 15.14 & 97.37 \\
\hline Lubelskie & 15.50 & 12.80 & 10.94 & 11.13 & 11.64 & 11.59 & 11.78 & 11.31 & 12.09 & 85.02 \\
\hline Lubuskie & 15.19 & 14.70 & 11.76 & 12.94 & 12.45 & 13.72 & 12.35 & 10.00 & 12.89 & 90.36 \\
\hline Łódzkie & 17.45 & 14.62 & 13.26 & 12.86 & 11.46 & 11.78 & 11.82 & 11.14 & 13.05 & 91.65 \\
\hline Małopolskie & 14.55 & 14.78 & 13.60 & 12.29 & 10.00 & 9.68 & 10.48 & 11.16 & 12.07 & 82.44 \\
\hline Mazowieckie & 16.91 & 14.45 & 14.51 & 10.57 & 10.70 & 11.53 & 12.20 & 12.09 & 12.87 & 89.46 \\
\hline Opolskie & 18.08 & 16.49 & 12.89 & 13.19 & 10.09 & 10.59 & 10.99 & 10.49 & 12.85 & 89.62 \\
\hline Podkarpackie & 12.12 & 11.98 & 10.90 & 10.05 & 10.99 & 10.38 & 10.99 & 8.92 & 10.79 & 71.29 \\
\hline Podlaskie & 24.83 & 20.97 & 16.11 & 15.94 & 16.36 & 12.84 & 14.01 & 15.19 & 17.03 & 115.53 \\
\hline Pomorskie & 17.07 & 17.64 & 15.46 & 14.33 & 12.21 & 14.29 & 11.38 & 11.12 & 14.19 & 101.43 \\
\hline Śląskie & 18.67 & 16.46 & 15.13 & 14.04 & 12.04 & 11.97 & 10.99 & 12.02 & 13.91 & 94.96 \\
\hline Świętokrzyskie & 16.94 & 17.02 & 15.12 & 14.80 & 9.26 & 9.10 & 7.28 & 11.87 & 12.68 & 86.21 \\
\hline Warmińsko-Mazurskie & 15.72 & 13.57 & 12.53 & 11.91 & 9.14 & 9.90 & 10.39 & 10.39 & 11.70 & 85.39 \\
\hline Wielkopolskie & 17.25 & 14.77 & 13.68 & 14.31 & 11.06 & 11.37 & 11.26 & 12.41 & 13.26 & 90.88 \\
\hline Zachodniopomorskie & 18.95 & 13.35 & 13.87 & 11.66 & 10.84 & 10.55 & 10.49 & 12.07 & 12.72 & 91.06 \\
\hline
\end{tabular}

est value of the prevalence rate for Poland was observed in 2008 (16.94 patients/100,000 inhabitants), in the following years the value gradually decreased to the level of 11.77 patients/100,000 inhabitants in 2015. In the eight-year follow-up period, the incidence rate of cervical cancer in Poland was 90.09 patients/100,000 inhabitants.
The highest annual and period prevalence rates were observed in the following voivodeships: Podlaskie (115.53 patientsper100,000inhabitantsintheperiod2008-2015 and 17.03 patients per 100,000 inhabitants on average annual) and Pomorskie (101.43 patients per 100,000 inhabitants in the period $2008-2015$ and 14.19 patients per 100,000 inhab- 


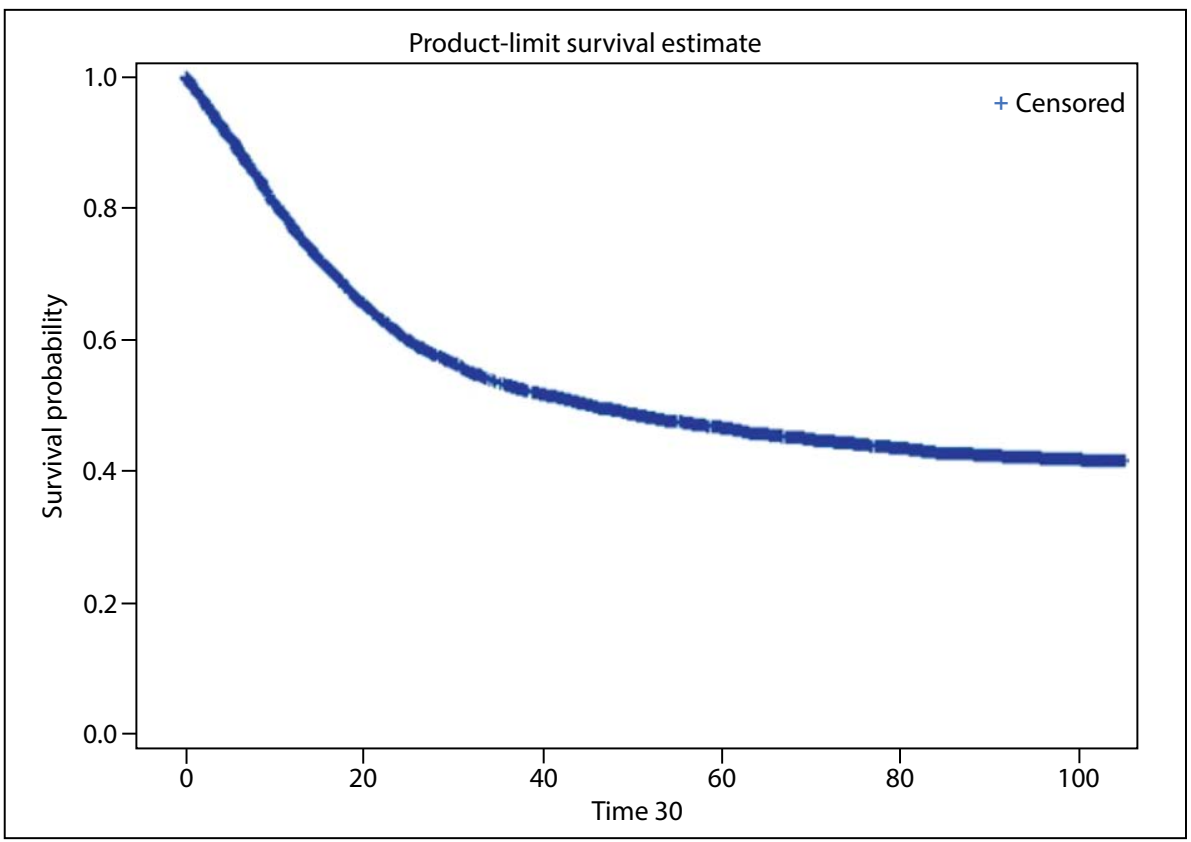

Figure 1. Kaplan-Meier estimation of overall survival in patients with cervical cancer undergoing chemotherapy

itants on average annual). High average annual value of this indicator was also found in Kujawsko-Pomorskie voivodeship (15.14) and Śląskie voivodeship (13.91), but the value of the eight-year prevalence for those voivodeships was lower than the value of that parameter in Podlaskie voivodeship and Pomorskie voivodeship. The lowest values of annual prevalence rate were observed in Dolnośląskie voivodeship (10.47) and Podkarpackie voivodeship (10.79) as well as the lowest value of the eight-year indicator was also observed in those voivodships, (78.87) and (71.29), respectively.

The median follow-up was 77.33 months. The survival curve was generated only for patients who received systemic therapy in the analyzed period. The number of analyzed observations was 5952, of which $49.06 \%$ were censored. Mean survival time was 55.12 months and its median 45.46 months. Annual survival time was observed in $76.79 \%$ of patients, two-year in $60.61 \%$; three-year in $53.08 \%$ and five-year in $46.65 \%$ (Fig. 1).

\section{DISCUSSION}

To the best of our knowledge, this is the most comprehensive epidemiological analysis of cervical cancer incidence and overall survival in patients after chemotherapy for cervical cancer. Within the collected material, numerical data of diagnoses according to ICD-10 classification and the type of hospital treatment in the form of chemotherapy were analyzed. Based on the collected data and comparison with the data on the population according to the Statistics Poland, the parameters describing overall survival (OS) were calculated and presented. The actual picture of prognoses for patients with cervical cancer in Poland was also obtained in the context of effectiveness of chemotherapy used, quality of treatment and degree of survival. The probability of overall survival is a determinant of the quality and effectiveness of cancer therapy in relation to that cancer in Poland.

In Europe, cervical cancer is responsible for about $13 \%$ of neoplasms in women and $4 \%$ of those cases are malignant neoplasms. Cervical cancer accounts for about $4 \%$ of female deaths in Poland [7].

Depending on the stage of cervical cancer according to FIGO classification and the patient's reproductive plans, there are several methods of its treatment which include: radical or fertility-sparing surgery, various surgical techniques, radiotherapy (brachytherapy and/or teletherapy), chemotherapy or a combination of those methods [7].

The analyzed data show that in the period 2008-2015, the Polish health care system recorded 83,100 women diagnosed with cervical cancer, which on average annual amounted to about 24,100 patients aged about 59 years. General data indicate a decrease in the number of cases in the analyzed period as the highest percentage of the incidence per 100,000 inhabitants in individual voivodships was recorded in 2008, which systematically decreased by about $30 \%$ in the analyzed eight-year observation period. In the scale of the entire period under observation, it can be observed that the highest percentage of cases was recorded in Podlaskie voivodship and Pomorskie voivodship as well as in Kujawsko-Pomorskie voivodeship. On the other hand, the 
lowest incidence rate for this type of neoplasm was recorded in Dolnośląskie voivodship and Podkarpackie voivodship.

In addition to the data describing the incidence of cervical cancer in Poland, the information on treatment with chemotherapy was also analyzed. According to the materials provided by the treating centres, about $40 \%$ of the analyzed total number of cases $(33,300)$ received treatment as part of hospital therapy. The observation period was about 78 months and the results of treatment of patients who received systemic chemotherapy were analyzed. In the group of 5,952 observed subjects, the median survival time was almost 4.5 years ( 55.1 months), and its median was 3.8 years. In the analyzed period, almost $77 \%$ of patients survived more than one year, $61 \%$ - two years, while only slightly more than half survived a three-year period and less than half (46.65\%) lived more than five years. This means that the median survival time after systemic chemotherapy does not reflect the actual survival rate and the data are very scattered. Compared to the data from the 1970s, the death rate from cervical cancer decreased by over $45 \%$. Nevertheless, mortality from this cancer in Poland is $70 \%$ higher than the average for the European Union countries $[1,5]$. Thus, the survival rates in Poland in comparison with the European Union countries as well as other developed countries indicate still insufficient quality of therapy, prevention or reporting errors. As indicated in the introduction, high incidence and mortality from cervical cancer in some regions of the world are mainly related to socioeconomic conditions, education, low health awareness and lack of primary and secondary prevention in women living in those areas. The data from WHO and the European Commission show that the number of cases of cervical cancer in Poland among women aged 55-59 years is still exceeding four times the number of cases in this group of women in Great Britain and over two times in Slovenia. However, in the same age group mortality in Poland is over five times higher than in Italy and over four times higher than in the Netherlands and Great Britain [7]. The above differences between the data on patients from Poland and other European countries indicate that the strategies of prophylaxis and chemotherapy used in Poland are still ineffective compared to the therapies used in other countries.

Almost all cervical cancer cases are linked to infection with high-risk human papilloma viruses (HPV) [2-4]. A common introduction of HPV vaccinations gives a real opportunity to reduce the number of cervical cancer cases. In 2020, < 30\% of low- and middle-income countries had implemented national HPV vaccination programs compared with $>80 \%$ of high-income countries [8]. Prophylaxis in the form of vaccine preventing HPV infection is the most effective method of reducing the incidence of cervical cancer. We can see examples of the effectiveness of such a program based on data from, for example, Australia [9]. HPV vaccinations have been available in Poland for almost 20 years, but it was not until January 2021 that HPV vaccination refunds for adolescent girls were introduced based on National Oncology Strategy. This creates the possibility of increasing the percentage of the population vaccinated against HPV, which will directly translate into a reduction in the incidence of cervical cancer.

Secondary prevention measures such as screening programs (the Pap tests) also lead to the drop in the cervical cancer death rate [10-12]. Whereas in Poland, since 2005, programs of early diagnosis of cervical cancer in the form of cytological tests are characterized by an unsatisfactory response from women to invitations - about $20 \%$, which results in presently high percentage of cases and diagnoses of clinically advanced forms of cervical cancer [12]. It is also believed that most of advanced-phase research on modern treatments of cervical cancer is carried out in the United Kingdom and the United States. Unfortunately, in those countries there is a lack of adequate research material in the form of advanced stage cases of cervical cancer that are recorded in Poland, which results in the lack of new drugs available in the case of late cancer diagnosis and initiation of cervical cancer treatment in Polish patients [5].

This study has several limitations. Firstly, our study is based on the data collected from the registry of the National Health Fund. The quality of reported data may influence the obtained results. However, the National Health Fund is the only institution in Poland collecting data on healthcare services provided to patients with cervical cancer throughout Poland, with a uniform method of reporting data. Secondly, our analysis is limited to an eight-year period and further analysis are needed to assess the impact of HPV vaccinations on the incidence and mortality related to cervical cancer. Nevertheless, our study also has practical implications. Epidemiological analysis of the incidence of cervical cancer in individual voivodeships can be used in planning the national oncological strategy and screening programs at the regional level. Moreover, data on overall survival may be the basis for further comparisons of the effectiveness of treatment between centers and the appointment of dedicated "cancer units" in the future.

\section{CONCLUSIONS}

1. In the years 2008-2015 in Poland, the level of cervical cancer incidence still exceeded the level recorded in other European Union countries (sometimes more than 4 times), while mortality in relation to other European countries was as much as $70 \%$ higher than an average for other countries.

2. The level of survival in the group of analyzed in 2008-2015 patients, who received systemic chemotherapy, 
was different depending on the survival period and very dispersed. Over a five-year survival period was observed only in less than half of the patients referred for treatment, which was more than four times less than the European average.

3. Relatively low survival rate of Polish women diagnosed with cervical cancer and receiving systemic chemotherapy may result from still insufficient prevention strategy, information and promotion of preventive examinations and underfunding of therapy in Poland.

4. Only systemic, coordinated and appropriately funded activities can contribute to lowering of the incidence rate (due to mandatory HPV vaccinations) and increasing the survival rate of Polish patients (due to early diagnosis and treatment) compared to other European countries.

\section{Conflict of interest}

All authors declare no conflict of interest.

\section{REFERENCES}

1. International Agency for Research on Cancer. Global Cancer Observatory. https://gco.iarc.fr/databases.php (2021.05.01).

2. World Health Organization. Health topics: Cancer. https://www.who. int/health-topics/cancer\#tab=tab_1 (2021.05.01).

3. Sung H, Ferlay J, Siegel RL, et al. Global Cancer Statistics 2020: GLOBOCAN estimates of incidence and mortality worldwide for
36 cancers in 185 countries. CA Cancer J Clin. 2021;71(3): 209-249, doi: 10.3322/caac.21660, indexed in Pubmed: 33538338.

4. Arbyn $M$, Weiderpass $E$, Bruni L, et al. Estimates of incidence and mortality of cervical cancer in 2018: a worldwide analysis. The Lancet Global Health. 2020; 8(2): e191-e203, doi: 10.1016/s2214-109x(19)30482-6, indexed in Pubmed: 31812369.

5. European Commission. ECIS - European Cancer Information System. https://ecis.jrc.ec.europa.eu/ (2021.05.01).

6. Michalska M. Epidemiologia raka szyjki macicy. . In: Spaczyńsk M, Kędzia W, Nowak-Markwitz E. ed. Rak szyjki macicy. Profilaktyka, diagnostyka i leczenie. Wyd Lek PZWL, Warszawa 2009.

7. Wojciechowska U, Didkowska J. Zachorowania i zgony na nowotwory złośliwe w Polsce. Krajowy Rejestr Nowotworów, Narodowy Instytut Onkologii im. Marii Skłodowskiej-Curie - Państwowy Instytut Badawczy. http://onkologia.org.pl/raporty/ (2021.05.01).

8. Brisson M, Kim J, Canfell K, et al. Impact of HPV vaccination and cervical screening on cervical cancer elimination: a comparative modelling analysis in 78 low-income and lower-middle-income countries. The Lancet. 2020; 395(10224): 575-590, doi: 10.1016/s0140-6736(20)300684, indexed in Pubmed: 32007141.

9. Saville AM. Cervical cancer prevention in Australia: Planning for the future. Cancer Cytopathol. 2016; 124(4): 235-240, doi: 10.1002/cncy.21643, indexed in Pubmed: 26619381.

10. Kuczborska K, Kacperczyk-Bartnik J, Wolska M, et al. Secondary cervical cancer prevention in routine prenatal care - coverage, results and lessons for the future. Ginekol Pol. 2019; 90(7): 396-402, doi: 10.5603/GP.2019.0068, indexed in Pubmed: 31392709.

11. Spaczyński M, Karowicz-Bilinska A, Kedzia W, et al. Costs of population cervical cancer screening program in Poland between 2007-2009. Ginekol Pol. 2010; 81(10): 750-756, indexed in Pubmed: 21117303.

12. Januszek-Michalecka L, Nowak-Markwitz E, Banach P, et al. Effectiveness of the National Population-Based Cervical Cancer Screening Programme in Poland--outcomes, problems and possible solutions 7 years after implementation. Ann Agric Environ Med. 2013; 20(4): 859-864, indexed in Pubmed: 24364469. 